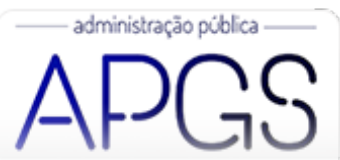

Administração Pública e Gestão Social ISSN: 2175-5787

apgs@ufv.br

Universidade Federal de Viçosa

Brasil

\title{
Um convite à internacionalização em prol da Gestão Pública Brasileira
}

Scelza Cavalcanti, Bianor

Um convite à internacionalização em prol da Gestão Pública Brasileira

Administração Pública e Gestão Social, vol. 11, núm. 4, 2019

Universidade Federal de Viçosa, Brasil

Disponível em: http://www.redalyc.org/articulo.oa?id=351560525015

Esta obra está bajo una Licencia Creative Commons Atribución-NoComercial-SinDerivar 3.0 Internacional. 


\section{Um convite à internacionalização em prol da Gestão Pública Brasileira}

Bianor Scelza Cavalcanti

Fundação Getulio Vargas, Brasil

bianor.cavalcanti@fgv.br
Redalyc: http://www.redalyc.org/articulo.oa? $\mathrm{id}=351560525015$

Certamente, é relevante e oportuno uma apresentação da Associação Internacional de Escolas e Institutos de Administração (IASIA, na sua sigla em inglês) nesta edição duplamente comemorativa, referente ao aniversário de cinco anos da Sociedade Brasileira de Administração Pública (SBAP) e de 10 anos da revista APGS.

O alto nível de internacionalização tornou-se um requisito absolutamente fundamental para o desenvolvimento de nossos programas no domínio da área de públicas, assim como em todas as demais.

Independentemente da maior facilidade de as ciências exatas gerarem e aplicarem o conhecimento universal, dado a maior unicidade de suas linguagens, métodos e técnicas, as maiores diferenciações das ciências sociais aplicadas não deixam de requerer os espaços de diálogo fundamental ao aprendizado no encontro das experiências diferentemente contextualizadas com o que possa representar o conhecimento universal.

Esses espaços do encontro internacional abrem as portas para as multifacetadas dimensões da internacionalização de nossos programas, quais sejam: o amplo fluxo de interação de alunos e professores nas diferentes modalidades de estudo discente e participação docente; $\mathrm{o}$ acesso a publicações especializadas acolhedoras das contribuições e pesquisas oriundas de fontes nacionais e regionais diferenciadas e de trabalhos de coautoria internacional; a participação em eventos ricos na interação profissional e pessoal; e instrumentos de acreditação que reconheçam e difundam a qualidade de programas dentro de rigorosos padrões internacionais de valor.

Estabelecida em 1961 e sediada em Bruxelas, vizinha ao Parlamento Europeu, a IASIA desponta como braço especializado do Instituto Internacional de Ciências Administrativas (IIAS) responsável pela integração de importantes organizações e indivíduos com atividades e interesses em temas relativos à educação e ao treinamento de administradores e gestores públicos. Tem como missão fortalecer a capacidade administrativa ao redor do mundo, promover excelência no processo de formação de quadros para a área da Administração Pública, e conduzir, discutir e disseminar boas práticas e pesquisas acadêmicas de ponta sobre governança e administração.

Nesse sentido, a IASIA procura prover oportunidades para o intercâmbio de informações, ideias, experiências e conteúdos através de suas conferências e seminários regulares, tendo em vista fomentar o engajamento com a comunidade internacional interdisciplinar; avançar no estudo sobre o setor público e sua gestão, incentivando a promoção do conhecimento e expertise por meio de seus working groups e publicações; incentivar o apoio regional e internacional em prol da educação e do treinamento no campo da gestão pública; e conduzir a acreditação em benefício de institutos e escolas, por meio de sua Comissão Internacional sobre Acreditação de Programas de Educação e Treinamento em Administração Pública (ICAPA).

Aberta para a participação de instituições e indivíduos com interesse na área da administração pública, sua credibilidade internacional se expressa na adesão de destacadas organizações oriundas de mais de 80 países dos cinco continentes, assim como no reconhecimento, por parte das Nações Unidas, do seu processo de acreditação com altíssimos padrões de excelência para a educação e formação em Administração Pública. 
Como parte do IIAS, a IASIA mantém profunda interação com as expressões regionais pertencentes ao Instituto, como o European Group for Public Administration (EGPA), o Asian Group for Public Administration (AGPA) e o Latin American Group for Public Administration (LAGPA), assim como com parcerias estratégicas consolidadas, a exemplo do The Middle East and North Africa Public Administration Research (MENAPAR); African Association For Public Administration and Management (AAPAM); United Cities and Local Government of Africa (UCLG-Africa); The Network of Institutes and Schools of Public Administration in Central and Eastern Europe (NISPAcee); American Society for Public Administration; Network of Schools of Public Policy, Affairs, and Administration (NASPAA); Organisation for Economic Co-operation and Development (OECD); United Nations Department of Economic and Social Affairs (UNDESA); e a United Nations Committee of Experts on Public Administration (UNCEPA).

Os 11 working groups da IASIA se constituem no coração e alma de suas atividades, agregando relevantes contribuições científicas em tópicos específicos, como: educação e treinamento; ética e cultura do setor público; reforma do setor público; governança e desenvolvimento subnacional; gênero, diversidade e equidade; liderança e governança; políticas públicas; recursos humanos; dimensões internacionais da administração pública; e globalização, territórios e integração. E por meio da International Review of Administrative Sciences (IRAS), a mais antiga revista acadêmica de administração pública focada em tópicos comparativos e internacionais, contribui para moldar a agenda futura da administração pública em todo o mundo, incentivando a reflexão sobre comparações internacionais, novas técnicas e abordagens, o diálogo entre acadêmicos e profissionais e debates sobre o futuro do próprio campo.

Cabe destacar também, para os acadêmicos e profissionais brasileiros, a atuação do Latin American Group for Public Administration (LAGPA), especialmente voltado para o fortalecimento das ligações entre especialistas latino-americanos em Administração Pública, visando promover ideias inovadoras, métodos e técnicas de modo a desenvolver a teoria e a gestão das políticas públicas. O LAGPA, assim como os demais braços regionais e parceiros estratégicos, mantém com frequência eventos bilaterais inter-regionais, promovendo também a circulação de ideias referentes ao seu contexto socioeconômico por meio da Revista de Administração Pública (RAP-LAGPA).

Sem dúvida, a comunidade de aprendizado acadêmica e profissional em torno do Campo de Públicas no Brasil em muito se beneficiará em explorar as multifacetadas dimensões da internacionalização disponibilizadas pela família IASIA-IIAS.

\section{BY-NC-ND}

